\title{
TELECENTROS COMUNITÁRIOS COMO FERRAMENTA DE APOIO NO PROCESSO DE INCLUSÃO DIGITAL
}

\author{
Júlio Lourenço de Sousa Filho - UEPB/UFPB - julio_clcuepb@ hotmail.com \\ Ana Carolina Costa de oliveira - IFPB - carolyneoliveira@ gmail.com
}

RESUMO. Diante das necessidades impostas pela nova sociedade da informação e da constante presença das tecnologias no cotidiano das comunidades, tem-se presenciado o surgimento de uma nova classe de cidadãos considerados digitalmente excluídos e, na tentativa de combater essa exclusão, várias organizações investem no sentido de disponibilizar centros de acesso às TICs. Com o intuito de conhecer a atuação desses centros de inclusão é que este trabalho propôs como objetivo analisar o papel dos telecentros comunitários como ferramenta de apoio no processo de inclusão digital da cidade A, sendo que para realização do estudo fez-se uso de uma pesquisa quantitativa do tipo descritiva, para a qual foi gerado um questionário e aplicado entre os usuários dos telecentros. Após o levantamento de informações e a análise dos dados, verificou-se que apenas uma parcela reduzida da população da cidade utiliza os recursos tecnológicos presentes nesses ambientes de inclusão, entretanto, entre os frequentadores, pôde-se observar que esses centros têm cumprido suas tarefas básicas, que é a disponibilização de acesso grátis às TICs.

Palavras-chave: Telecentros Comunitários. Inclusão Digital. Processo de Inclusão.

\section{COMMUNITY TELECENTERS AS A SUPPORT TOOL IN THE PROCESS OF DIGITAL INCLUSION}

\begin{abstract}
Faced with needs imposed by the new information society and the constant presence of technology in daily of communities, has seen the emergence of a new citizens of class considered digitally excluded, and in attempt of combat this exclusion, many organizations, invest in order to provide access centers TIC. In order to know the work of these centers include proposed that this work aimed at analyze the role of community telecenters as a support tool in the process of digital inclusion A City, and for the study made if using a quantitative descriptive of the type for which a questionnaire was generated and applied between users of the telecenters of that city. After survey of information and analysis of data, it was found that only a small proportion of the population uses the technology resources present in these environments of inclusion, however, among attend, it could noted that these centers have completed their tasks, which is the provision of free access.
\end{abstract}

Keywords: Community Telecenters. Digital Inclusion. Inclusion Process.

\section{INTRODUÇÃO}

Na sociedade atual, denominada "sociedade da informação" ou "sociedade do conhecimento", tem-se observado a presença cada vez mais constante dos computadores e da internet em todos os segmentos da vida em sociedade, seja como meio de trabalho, entretenimento, educação, relacionamento ou em uma das várias possibilidades de uso.

Essa nova era da informação requer indivíduos criativos, dotados de uma capacidade avaliativa que os tornem aptos a criticar construtivamente, pensar, aprender sobre aprender, trabalhar em grupo, interagir de forma harmoniosa com os meios 
digitais, além de conhecer seus próprios potenciais. Um indivíduo que, atento às mudanças da sociedade, é capaz de se adaptar, melhorar e depurar suas ideias e ações (VALENTE, $s . d$ ).

Entretanto, essa sociedade do conhecimento, que apresenta um ambiente globalizado baseado em comunicação, informação e aprendizagem, em que a aquisição de informações está cada vez mais focada no acesso aos meios computacionais, principalmente no acesso à internet, tem gerado um novo tipo de exclusão, a denominada exclusão digital (SCHWARZELMÜLLER, 2005).

$\mathrm{Na}$ tentativa de minimizar as desigualdades oriundas dessa sociedade da informação, principalmente no tocante às desigualdades de acesso aos meios digitais pelos moradores das comunidades mais carentes, diversas instituições, sejam elas federais, estaduais, municipais, ONGs e até mesmo da iniciativa privada, têm investido na implantação dos chamados telecentros comunitários, agindo esses, segundo Laipelt [et al.] (2006), como promotores de acesso à informação e comunicação.

Junto ao processo de implantação dos telecentros surge a oportunidade de o indivíduo, antes excluído digitalmente, se inserir nessa nova sociedade da informação como um cidadão atuante e dotado dos conhecimentos e habilidades necessários para se adaptar de forma plena ao meio social (FERRO e MAGNONI, 2009).

Há inúmeras afirmações que relatam a importância dos telecentros comunitários para o desenvolvimento digital dos moradores de uma região, entretanto, torna-se indispensável uma investigação mais detalhada que possa confirmar na prática se realmente esses centros estão cumprindo a função social para a qual foram implantados.

$\mathrm{Na}$ tentativa de avaliar a atuação desses ambientes de inclusão frente às comunidades nas quais estão inseridos, esta investigação tem como objetivo analisar o papel dos telecentros comunitários como ferramenta de apoio no processo de inclusão digital da cidade $\mathrm{A}$.

\section{EIXO TEMÁTICO}

Nesta seção, serão apresentadas algumas abordagens teóricas que vão servir de base para se alcançar os objetivos propostos neste artigo, destacando-se como temas os telecentros, a inclusão e a exclusão digital, além de vários pontos relacionados ao processo de inclusão.

\subsection{TELECENTROS}

Diante de tantos meios de informação e de tantos ambientes de acesso a esses recursos, fica difícil apresentar uma definição precisa do que são telecentros. Não se pode considerar um telecentro apenas como um ambiente de acesso às tecnologias, e sim como um espaço público que disponibiliza acesso e uso de informações através das TICs, tendo como finalidade a capacitação de indivíduos, redução das desigualdades econômicas e sociais, e a promoção da cidadania (BARRETO [et al.], 2008).

Com o exposto, julga-se que a essência das atividades desenvolvidas nos telecentros não estão relacionadas apenas ao oferecimento do acesso às TICs, ainda que essa seja a preocupação fundamental, mas em promover um uso adequado dessas ferramentas de forma que possa capacitar seus usuários para a exploração das potencialidades das tecnologias presentes no seu meio social (LAIPELT [et al.], 2003).

Ainda segundo os autores, os telecentros podem ser caracterizados de acordo com o tipo de atividades e de serviços que desenvolvem ou pela forma como são administrados, entretanto, para melhor análise, dividiram esses centros em três V. $10 \mathrm{~N}^{\mathrm{o}} 1$, julho, 2012 
categorias que englobam todos os tipos de telecentros, como é apresentado no Quadro 1.

\begin{tabular}{|c|l|}
\hline $\begin{array}{c}\text { GRUPOS DE } \\
\text { TELECENTROS }\end{array}$ & \multicolumn{1}{c|}{ DEFINIÇÃO } \\
\hline $\begin{array}{c}\text { Telecentros } \\
\text { Comerciais }\end{array}$ & $\begin{array}{l}\text { São desenvolvidos e administrados por instituições privadas e proporcionam acesso } \\
\text { público às TICs mediante o pagamento de uma tarifa (LAIPELT; [et al.], 2003). }\end{array}$ \\
\hline $\begin{array}{c}\text { Telecentros } \\
\text { Cívicos }\end{array}$ & $\begin{array}{l}\text { São os presentes nas bibliotecas públicas, escolas, universidades e outras instituições } \\
\text { cívicas, e que o eixo principal de trabalho nessas organizações não é a atividade do } \\
\text { telecentro como o tal, já que esse é oferecido ao público como complemento aos seus } \\
\text { outros serviços culturais, educativos e recreativos (GÓMEZ [et al], 1999). }\end{array}$ \\
\hline Telecentros & $\begin{array}{l}\text { São iniciativas que proporcionam acesso público às TICs, sobretudo a internet, } \\
\text { garantindo acesso universal para captação, geração, prospecção e distribuição do } \\
\text { conhecimento, servindo para facilitar, desenvolver e estimular a participação cidadã na } \\
\text { comunidade (LAIPELT; [et al.], 2003). }\end{array}$ \\
\hline
\end{tabular}

Quadro 1: Categorias predominantes de telecentros.

Fonte: Pesquisador do estudo (2011).

De posse do conhecimento das categorias de telecentros, definidas por Laipelt [et al.] (2003), afirma-se que o telecentro ou uma de suas várias denominações, surge como uma iniciativa de baixo custo capaz de disponibilizar acesso e uso de informações, através das TICs, em comunidades de menor potencial aquisitivo (BARRETO [ et al.], 2008).

Por se tratarem de núcleos capazes de gerar a fácil aquisição de informações pelos grupos carentes, o uso dos telecentros permitirá não só aos alunos, mas a toda comunidade, superar as deficiências da falta de informação e comunicação (PACHECO, 2011).

Em virtude do que foi mencionado e seguindo as categorias de telecentros definidas por Laipelt [ et al.] (2003), neste artigo serão analisados os telecentros comunitários. Na sequência discutem-se algumas abordagens e conceitos sobre a inclusão digital, bem como do seu oposto.

\subsection{INCLUSÃO DIGITAL}

Com o avanço cada vez mais constante dos recursos tecnológicos e com a crescente produção/distribuição de informação sob meios digitais, viu-se surgir nos últimos anos, e a cada dia mais expressivamente, a necessidade de se ter cidadãos cada vez mais capacitados, e os que não se preparam ou não conseguem acompanhar as exigências dessa sociedade do conhecimento acabam por ficar excluídos (SILVA; PESTANA, s.d.).

De acordo com a UNESCO (2008) inclusão digital significa possibilitar acesso à rede mundial de computadores, promovendo o desenvolvimento das pessoas por meio do uso das tecnologias de informação e comunicação.

Assim sendo, inclusão digital não deve ser encarada apenas como um modelo de ensino técnico, no qual os alunos aprendem a usar determinadas ferramentas, softwares ou acessar a internet, mas como modelo de inclusão, que estimula a compreensão e a transmissão de informações, criando mecanismos para uma maior participação social e cultural dos indivíduos (LEMOS [et al.], 2005).

Nessa linha de raciocínio Ferro [et al.] (2009) afirma que a inclusão digital promove não só o acesso, como também o uso e a apropriação das novas tecnologias digitais, visando satisfazer as necessidades das comunidades, gerar conhecimentos e o fortalecimento das capacidades pessoais. Desse modo, não é simplesmente ter acesso às 
TICs, é necessário saber usá-las e, através de uma visão crítica, saber selecionar as informações pertinentes, dentre uma gama de outras disponíveis (PEREIRA, 2004).

Destacando-se ainda aspectos sobre exclusão digital, Emygdio (s.d.) aponta que ela não se dá apenas pela falta de acesso físico aos computadores, acessórios e conexões, como também pela falta de recursos e ferramentas adicionais que permitem um uso mais eficiente e adequado das tecnologias, pois, segundo o referido autor, a inclusão não é proporcionada pelo mero provimento da infraestrutura de acesso e sim por um trabalho de orientação, que apenas começa com a implantação da infraestrutura.

Levando-se em conta a relação entre exclusão social e digital, considera-se que da mesma forma que exclusão digital é vista como consequência da exclusão social, ela por sua vez, contribui de forma atuante para o aumento das desigualdades sociais (FUSER, 2007).

Compartilhando desse pensamento, Ferro [et al.] (2009) afirma que a exclusão socioeconômica desencadeia a exclusão digital e, em contrapartida, a exclusão digital aprofunda ainda mais a exclusão socioeconômica. Em vista dos aspectos observados pode-se afirmar que a inclusão digital e inclusão social são inseparáveis, atuam uma ao lado da outra crescendo e desenvolvendo-se juntas (EMYGDIO, s.d.).

Pôde-se observar algumas ideias pertinentes ao tema inclusão digital, bem como sobre o seu avesso, a exclusão digital. Além de afirmativas que comprovam a forte relação entre a inclusão digital e a inclusão social, cultural e até mesmo econômica. Posteriormente, serão apresentadas algumas abordagens acerca do processo de inclusão digital, bem como da forma em que esse processo se desenvolve individualmente e perante a sociedade.

\subsection{PROCESSO DE INCLUSÃO DIGITAL}

Antes de entrar no assunto "processo de inclusão digital" é importante ter em mente o que significam essas palavras isoladamente. Ferreira (2001) considera o processo como uma sucessão de estados, de transformações, em outra definição julga que é a forma pela qual se realiza ou executa alguma coisa.

Considerando-se mais em termos de inclusão digital, Rebêlo (2005) afirma que incluir digitalmente não é apenas dotar as pessoas de conhecimento em informática, mas também proporcionar uma melhora nos quadros sociais, uma maior participação comunitária e a formação de uma visão crítica a partir da utilização dos computadores.

Compartilhando dessa ideia, Schwarzelmüller (2005) aponta que o processo de inclusão digital não se dá apenas por meio do acesso as tecnologias, e sim pela forma como essa tecnologia vai ser utilizada para atender as necessidades da sociedade e fortalecer o pensamento crítico, pois o papel mais importante do processo de inclusão digital deve ser a sua atuação em favor da promoção social.

Comungando desse pensamento, Rondelli (2003) afirma que são necessários quatro passos para promover a inclusão digital. Que são: 1) disponibilizar computadores e equipamentos tecnológicos conectados em rede; 2) as pessoas que serão incluídas precisam ter o que fazer com os equipamentos; 3) deve haver uma organização governamental que oriente todo o trabalho, desde a fabricação de hardwares e softwares, até o modo como serão apresentadas essas tecnologias ao usuário final e; 4) proporcionar maior interação entre os usuários das tecnologias.

Portanto, incluir não deve ser apenas dotar os usuários de uma formação técnica para uso dos equipamentos e aplicativos, e sim, um trabalho que vise desenvolver 
habilidades cognitivas que tornam um indivíduo capaz de transformar informações em conhecimento e utilização em apropriação (LEMOS [et al.], 2005).

Nesta seção, foram apresentados alguns conceitos e informações que tentaram demonstrar os conhecimentos relacionados ao processo de inclusão digital, bem como ressaltar as relações existentes entre os processos de inclusão digital e social.

\section{REFERENCIAL METODOLÓGICO}

Tendo em vista a iniciativa de várias organizações, sejam Federais, Estaduais, Municipais, ONGs e até mesmo pela iniciativa privada, em implantar telecentros como forma de promover a inclusão, buscou-se neste estudo, analisar o papel dos telecentros comunitários como ferramenta de apoio no processo de inclusão digital da cidade A.

Para a consecução do objetivo geral, fez-se necessário a realização dos seguintes objetivos específicos: Observar o que descrevem os autores acerca dos telecentros comunitários; Identificar o perfil dos usuários dos telecentros; Coletar informações acerca de como vem sendo a atuação do telecentro em favor da inclusão digital; Analisar, a partir dos dados adquiridos, a atuação dos telecentros no processo de desenvolvimento social e digital dos seus usuários.

A efetivação desse estudo teve suas bases fundamentadas numa pesquisa do tipo descritiva, firmando-se como amostra escolhida, para a realização da pesquisa, a não probabilística e intencional, o que necessariamente levou a um estudo de caso.

Os centros escolhidos para pesquisa foram 02 (dois) telecentros presentes na cidade A. A escolha da cidade para realização desse estudo se deu em virtude de ser a cidade natal do pesquisador e pelo seu desejo de analisar qual a influência dos telecentros comunitários no processo de inclusão digital dos moradores da cidade.

A cidade, aqui identificada como "cidade A", está localizada no sertão paraibano em uma região denominada vale do Piancó, possuindo, de acordo com o Instituto Brasileiro de Geografia e Estatística (IBGE), 23.192 (vinte e três mil, cento e noventa e dois) habitantes.

Inicialmente e com a finalidade de obter maior sucesso na pesquisa, realizou-se um estudo teórico. Para o estágio de coleta de informações fez-se uso de um questionário, contendo 10 questões, contendo em seu corpo perguntas de investigação do perfil, forma de uso do telecentro e questões no tocante ao processo de inclusão.

A aplicação do questionário deu-se entre os meses de setembro e outubro do ano de 2011, em ambos os telecentros e nos turnos manhã e tarde, ficando o horário noturno, bem como os fins de semana, fora dessa pesquisa por não haver funcionamento dos telecentros nesses horários e dias, respectivamente.

De acordo com informações levantadas a partir de dados presentes nos telecentros, o número de acessos mensais, aos centros de inclusão, fica em torno de 600 acessos, dos quais $60 \%$ são feitos pelos mesmos usuários, ficando um total de $40 \%$, equivalente a 240 pessoas, que são frequentadoras do telecentro, atuando esse quantitativo como o correspondente ao universo da pesquisa.

Diante do exposto, fez-se uso de um cálculo probabilístico para, de acordo com o universo de estudo, determinar a amostra necessária para o bom provimento da observação e consequentemente, a delimitação da quantidade de questionários a serem aplicados, portanto, dos 600 usuários correspondentes ao universo da pesquisa, foram aplicados 53 questionários, número correspondente à amostra necessária para o estudo. Ficando, portanto, constatada a representatividade, e consequentemente, a validade da 
pesquisa realizada.

Posteriormente à obtenção dos questionários, fez-se a tabulação dos dados obtidos, com o auxílio do Microsoft Excel, e sucessivamente a análise desses dados, levando-se em conta o propósito do trabalho para o qual a investigação foi realizada.

\section{DADOS E ANÁLISE DA PESQUISA}

Nesta seção, apresentam-se os dados coletados na pesquisa, bem como sua análise e as relações existentes entre as questões levantadas e os objetivos específicos propostos, buscando-se, ao fim do estudo, alcançar os resultados planejados na formulação do objetivo geral desta pesquisa.

\subsection{PERFIL DOS USUÁRIOS DOS TELECENTROS}

Seguindo a análise dos dados coletados na pesquisa, pode-se verificar o perfil dos usuários desses centros, bem como as relações entre o uso dos telecentros e o processo de desenvolvimento digital dos usuários. De posse dos dados, constatou-se que a maioria dos usuários, aproximadamente 56,60\%, são do sexo feminino, o que representa uma ligeira vantagem em relação aos acessos por pessoas do sexo masculino.

Conforme se pode verificar na Figura 3, apresentada a seguir, no que se refere à ocupação dos visitantes, verificou-se que, em sua maioria são estudantes, com aproximadamente $77,36 \%$ dos indagados, tendo apenas $13,21 \%$ respondido que tem alguma ocupação de vínculo empregatício. Portanto, tornando-se notável a maior utilização dos telecentros por quem está frequentando o ambiente escolar.

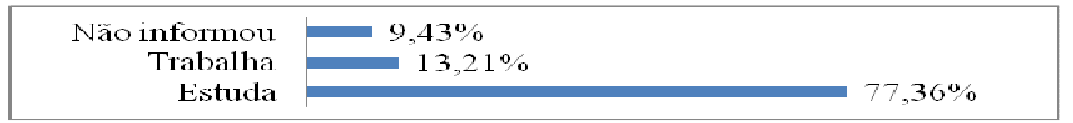

Figura 3: Ocupação dos usuários dos telecentros.

Fonte: Pesquisador do estudo (2011).

É possível relacionar ainda, o uso desses centros de inclusão à faixa etária dos seus utilizadores, destacando-se os visitantes com idades compreendidas entre 14 e 17 anos, ficando em último lugar, em relação ao acesso, os cidadãos com idades acima dos 21 anos. A Figura 4 expressa o uso dos telecentros levando-se em conta a idade dos seus acessantes.

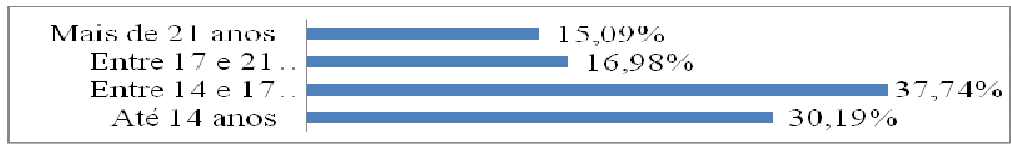

Figura 4: Faixa etária dos usuários dos telecentros comunitários.

Fonte: Pesquisador do estudo (2011).

Em relação ao nível de escolaridade dos entrevistados, quase metade $(49,06 \%)$ está cursando ou concluiu o ensino médio, vindo com uma porcentagem um pouco inferior, os estudantes do ensino fundamental, representando um total de 45,28\% dos indagados, não apresentando, nesta pesquisa, usuários sem escolaridade ou com pósgraduação. Os dados completos desse levantamento podem ser visualizados na Figura 5.

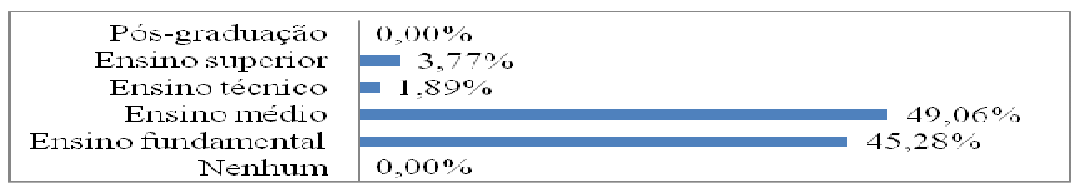

Figura 5: Nível de escolaridade.

Fonte: Pesquisador do estudo (2011). 
Quando questionados sobre a renda familiar mensal, 26,42\% não souberam informar, sendo ainda que $9,43 \%$ responderam que a renda familiar mensal é inferior a um salário mínimo, estando como maiores acessantes $(33,96 \%)$, os indivíduos com renda compreendida entre 1 e 2 salários. Vale destacar que apenas 7,55\% dos entrevistados apontaram possuir renda superior a 5 (cinco) salários, demonstrando que os telecentros são ambientes dominados pelas classes mais carentes. Os resultados completos dessa análise estão expostos na Figura 6.

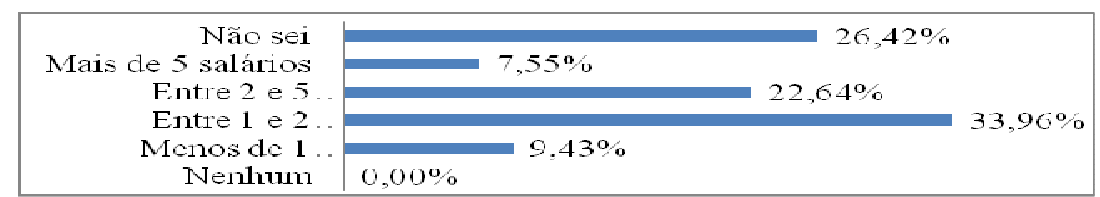

Figura 6: Renda bruta familiar

Fonte: Pesquisador do estudo (2011).

A seguir serão analisadas as variáveis que demonstram as relações existentes entre o uso dos telecentros e a inclusão social, digital e cultural dos moradores da comunidade na qual o telecentro está inserido.

\subsection{TELECENTROS VERSUS INCLUSÃO DIGITAL}

Um bom fator para relacionar a importância dos telecentros para a inclusão digital dos moradores de uma região, é saber o quanto esses proporcionam condições de os cidadãos mais marginalizados ou simplesmente pertencente às classes mais baixas da sociedade terem acesso aos meios tecnológicos e informacionais que norteiam a sociedade da informação.

Inicialmente buscou-se identificar o motivo que levou os usuários dos telecentros a fazerem uso dos meios tecnológicos presentes nesse ambiente. Após a análise dos dados (Figura 7) verificou-se que a maior parte dos entrevistados $(41,51 \%)$, frequentavam esses centros por serem locais de acesso grátis à rede mundial de computadores, tendo ainda um percentual de $13,21 \%$ que indicaram que usam este ambiente devido à velocidade da internet.

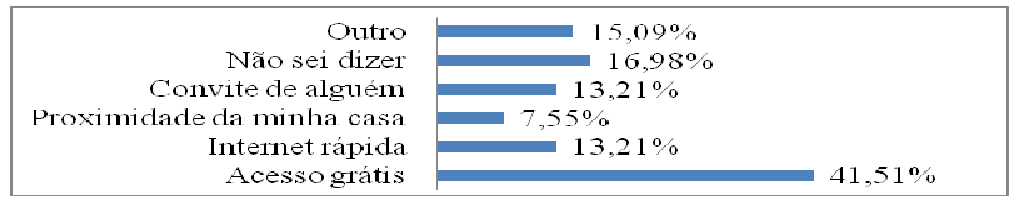

Figura 7: Motivação para uso do telecentro.

Fonte: Pesquisador do estudo (2011).

Quando indagados sobre o tempo, contado em horas por semana, que faziam uso dos recursos disponíveis nesse centro, mais da metade, aproximadamente 52,83\% dos entrevistados, respondeu que usava entre 1 e 3 horas semanais, sendo que essa porcentagem decaia em razão do aumento da quantidade de horas semanais de acesso, sendo que nenhum dos entrevistados afirmou frequentar o telecentro por mais de 11 horas semanais, como apresentado na Figura 8.

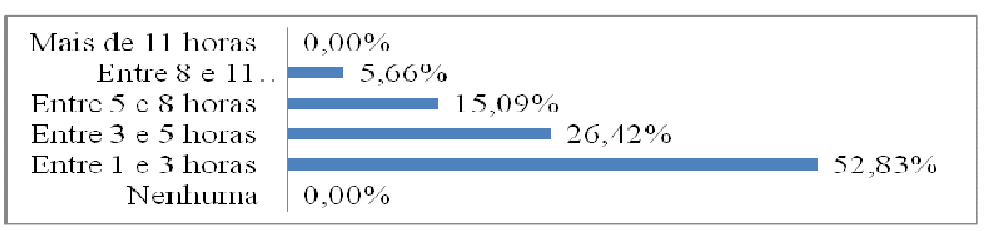


8

Figura 8: Horas de acessos semanais.

Fonte: Pesquisador do estudo (2011).

Para averiguar a importância desses centros de inclusão, foi imprescindível conhecer em que locais, além dos telecentros, seus usuários acessavam a internet. Os resultados (Figura 9) mostram que, quase $80 \%$ dos questionados tinham acesso à internet fora do telecentro, sendo que esse ambiente atuava como único provedor de acesso para cerca de $20,25 \%$ de seus frequentadores, demonstrando que apesar do uso por uma parcela reduzida da população da cidade, entre seus visitantes, o telecentro estava dando oportunidades de se inserirem digitalmente na sociedade da informação.

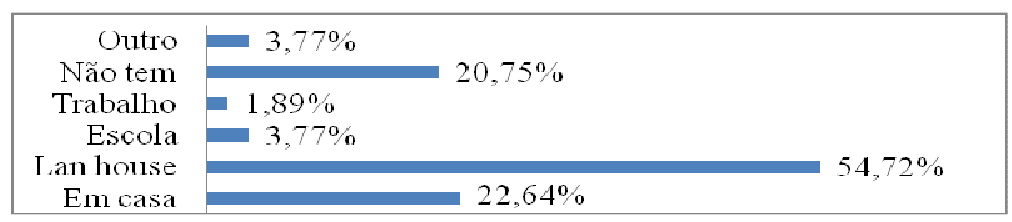

Figura 9: Locais de acesso à Internet fora do telecentro.

Fonte: Pesquisador do estudo (2011).

Com a intenção de verificar de que forma esses ambientes de inclusão podiam atrair mais visitantes e/ou servir de forma mais satisfatória para seus frequentadores, fez-se uma indagação, de resposta aberta, na qual o questionado pôde responder livremente o que mudaria no telecentro para melhorar os serviços oferecidos.

De posse das respostas verificou-se que, entre os resultados pertinentes, destaca-se a disponibilização de impressoras, acesso liberado para redes sociais (Orkut e msn), oferecer cursos de computação, abrir à noite e nos fins de semana, disponibilizar mais computadores e mudar o sistema operacional, tendo em vista os telecentros usarem um sistema Linux. Na seção seguinte são apresentados os resultados da pesquisa no que diz respeito à atuação dos telecentros comunitários no processo de inclusão digital.

\subsection{TELECENTROS E O PROCESSO DE INCLUSÃO DIGITAL E SOCIAL}

Tendo em vista a função dos telecentros comunitários, verificou-se neste estudo, como esse centro tem atuado no processo de inclusão social, cultural e digital dos grupos sociais pertencentes a comunidades sob suas atuações.

Como primeira questão imposta sobre o tema, buscou-se verificar quais as atividades que os usuários desenvolvem no telecentro. Após a análise dos dados, constatou-se que $75,47 \%$ dos entrevistados afirmaram que usam esse ambiente para fazer pesquisas na Internet, demostrando a importância desses centros como meios de busca de informações e conhecimentos.

Em segundo lugar nessa questão, aparecem com porcentagens iguais, os que fazem trabalhos e escrevem textos e os que enviam e recebem mensagens ambos com um percentual de $35,85 \%$ dos indagados, firmando-se a ideia da atuação dos telecentros não apenas como disponibilizadores de acesso, mas também como provedores de comunicação e facilitadores da execução dos trabalhos pessoais. A Figura 10 apresenta mais informações para o entendimento do estudo.

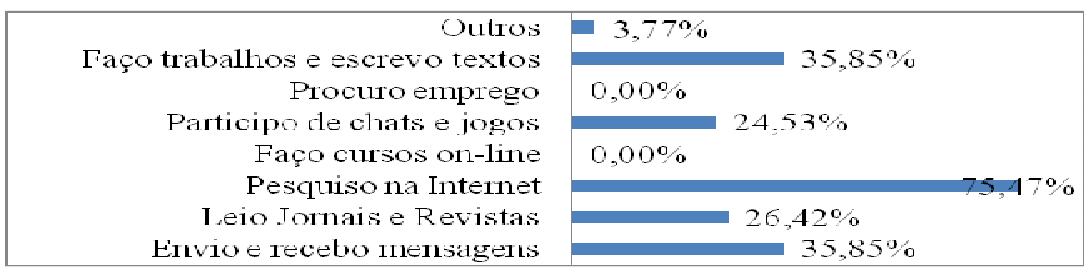


9

Figura 10: Atividades desenvolvidas nos telecentros.

Fonte: Pesquisador do estudo (2011).

Questão similar a anterior foi levantada com o propósito de identificar os tipos de páginas acessadas pelos frequentadores dos telecentros, destacando-se as páginas de pesquisa, com $77,36 \%$ dos acessos, e educação com $43,40 \%$, levando-se a julgar que os usuários desses centros estão mais interessados na busca do conhecimento.

Vale ressaltar ainda, conforme pode-se visualizar na Figura 11, o alto número de usuários que afirmam acessar sites de diversão, que compreendem sítios de jogos, rádios on-line, sites de música, vídeos entre outros, ficando esse quesito com um total de $35,85 \%$ das páginas visitadas pelos frequentadores dos telecentros.

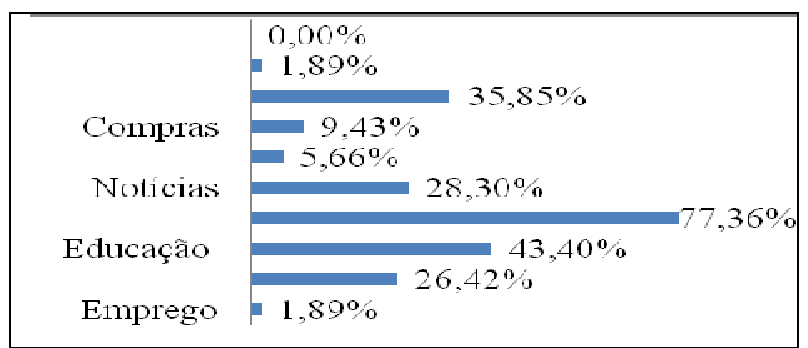

Figura 11: Tipos de páginas acessadas nos telecentros.

Fonte: Pesquisador do estudo (2011).

Quanto à participação dos indivíduos nas relações de troca de informações e na geração de conhecimento, investigou-se as atuações como membros geradores e disponibilizadores de informações e conhecimentos, o que demonstrou que mais da metade $(56,60 \%)$ dos usuários do telecentro não posta informações na rede mundial de computadores, sendo, portanto, apenas consumidores de serviços e informações.

Entretanto, existe um grupo de usuários $(30,19 \%)$ que apontaram usar alguma rede social, a exemplo do Orkut e/ou Facebook, para postar notícias e informações, portanto, acabam de alguma forma produzindo e compartilhando informações pela Internet. A Figura 12, criada a partir dos resultados dessa indagação, apresenta os detalhes dessa informação.

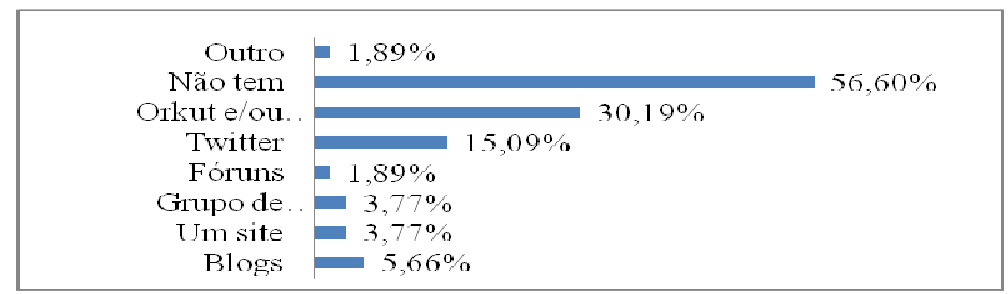

Figura 12: Redes sociais onde postam informações.

Fonte: Pesquisador do estudo (2011).

Por fim, buscou-se avaliar as ações desenvolvidas nos telecentros, a fim de capacitar os moradores da região para que haja uma melhor utilização dos meios e recursos tecnológicos presentes na comunidade. Com a análise dos dados, identificou-se que $100 \%$ dos usuários entrevistados não fizeram nenhuma oficina ou curso de capacitação disponibilizado pelos telecentros comunitários, demonstrando que, embora estejam disponibilizando acesso, não estão capacitando os usuários para que possam fazer melhor uso das tecnologias ali presentes.

\section{CONSIDERAÇÕES FINAIS}

V. $10 \mathrm{~N}^{\mathrm{o}} 1$, julho, 2012 
Levando-se em conta a análise dos dados adquiridos na pesquisa realizada nos telecentros comunitários da cidade A e assumindo-se como universo da pesquisa os usuários desses telecentros, pode-se observar que esses ambientes têm cumprido apenas suas tarefas mais básicas, que é a disponibilização de acesso grátis e de qualidade à rede mundial de computadores para os moradores das comunidades mais carentes.

Contudo, a função dos telecentros comunitários não deve se restringir a simples disponibilização de acesso aos meios, são necessárias ações que capacitem os moradores da região e usar e apropriar-se desses recursos, fazendo uso dessas ferramentas para aquisição de conhecimentos e habilidades necessárias para seu bom desenvolvimento como membro da sociedade da informação.

Para que ocorra esse desenvolvimento pessoal são necessárias ações que ofereçam oportunidades dos indivíduos adquirirem tais conhecimentos e habilidade, e para isso, é imprescindível o oferecimento de cursos e oficinas, o que, de acordo com os entrevistados, não tem ocorrido nesses centros. Quando questionados se já realizaram e, se não, o porquê, os responsáveis pelos respectivos telecentros informaram que, em um dos centros já havia ocorrido 2 (dois) minicursos de informática, quanto ao outro centro, apontaram que o oferecimento de cursos e oficinas estava previsto para ter início no mês subsequente ao término desta pesquisa.

Por outro lado, tomando-se como universo da pesquisa todos os moradores da cidade em questão, tais centros de inclusão não tem cumprido de forma satisfatória sua função social, tendo em vista que apenas pouco mais de $1 \%$ (um por cento) dos indivíduos dessa cidade acessam mensalmente esses telecentros comunitários.

Diante do conhecimento obtido através da realização do estudo, induz-se que é necessário o desenvolvimento de ações que estimulem, os atuais visitantes, e incentivem os indivíduos que ainda não são frequentadores assíduos desses ambientes de inclusão a fazerem uso constante e tirarem o maior proveito possível das tecnologias e, consequentemente, dos meios proporcionados por ela e presentes nesses centros.

Este trabalho poderá servir de base para que os setores competentes da sociedade tomem providências no sentido de disponibilizar melhores serviços que visem à obtenção de um maior desenvolvimento digital, social e cultural dos indivíduos pertencentes às classes menos favorecidas da sociedade, bem como para que estudiosos do assunto busquem alternativas que estimulem e incentivem os cidadãos de uma comunidade carente a frequentarem mais constantemente os telecentros comunitários.

\section{REFERENCIAS}

BARRETO, A. M.; PARADELLA, M. D.; ASSIS, S. Bibliotecas públicas e telecentros: ambientes democráticos e alternativos para a inclusão social. Ciência da Informação, Brasília, v.37, n.1, p.27-36, jan.-abr. 2008.

EMYGDIO, R. F. Programa a vez do mestre: exclusão digital x exclusão social. Disponível em: <www.avm.edu.br/monopdf/31/roberto\%20ferreira\%20emygdio.pdf>. Acesso em: 03 de set. de 2011.

FERREIRA, A. B. de H. Miniaurélio século XXI: o minidicionário de língua portuguesa. $5^{\text {a }}$ ed. Ver. Ampliada. - Rio de Janeiro. Nova Fronteira. 2001. FERRO, G. C.; MAGNONI, A. F. Telecentro como ferramenta de inclusão social. Lecotec, II simpósio de comunicação, tecnologia e educação cidadã. Bauru - SP, nov. 2009. 
FUSER, B. Inclusão digital: o telecentro como equipamento de comunicação comunitária. In: Anais do XXX Congresso Brasileiro de Ciências da Comunicação. São Paulo: 2007.

GÓMEZ, R.; HUNT, P.; LAMOUREUX, E. Telecentros en la Mira: cómo pueden contribuir al desarrollo social. In.: Revista Latinoamericana de Comunicación Chasqui, 1999.

INSTITUTO BRASILEIRO DE GEOGRAFIA E ESTATÍSTICA. 2010. Disponível em: <www.ibge.gov.br/cidadesat/topwindow.htm?1>. Acesso em: 04 de out. de 2011. LAIPELT, R. do C. F. et al. Informação e comunicação para cidadania: qualificando monitores para telecentros comunitários. Florianópolis, novembro. 2003.

LAIPELT, R. et al. Inclusão digital: laços entre bibliotecas e telecentros. Inf. \& Soc.:Est., João Pessoa, v.16, n.1, p.223-229, 2006.

LEMOS, A.; COSTA, L. F. Um modelo de inclusão digital. In.: Revista de Economía Política de las Tecnologías de la Información y Comunicación. Vol. 8, n. 6, 2005. PACHECO, C. de M. dos S. Telecentro: ferramenta de mudança na educação da rede municipal de São Luís do Maranhão. Anais do III Simpósio sobre Formação de Professores - SIMFOP. Tubarão, março. 2011.

PEREIRA, P. M. S. Impactos sócio-culturais de telecentros comunitários: o caso do telecentro Chico Mendes. Porto alegre. V. 10, n. 2, p 375.388 jul.- dez. 2004.

REBÊLO, P. Inclusão digital: $o$ que é e a quem se destina. 2005.

RONDELLI, E. Quatro passos para a inclusão digital: I-coletiva. [S.l: S.n.], 2003. SANTOS, Vanice dos. CANDELORO, Rosana J. Trabalhos acadêmicos: uma orientação para a pesquisa e normas técnicas. Porto Alegre, RS: AGE, 2006.

SCHWARZELMÜLLER, A. F. Inclusão digital: uma abordagem alternativa. In: CINFORM - Encontro Nacional de Ciência da Informação, Salvador, 2005.

SILVA, C. F. da; PESTANA, I. C. A sociedade da informação: a criança com deficiência e as novas tecnologias. Educação, Ciência e Tecnologia.

UNESCO. Tecnologia, informação e inclusão: Brasil no rumo da inclusão. V. I, n.1, 2008.

VALENTE, J. A. Análise dos diferentes tipos de software usados na educação. In: (Org.). O computador na sociedade do conhecimento. Brasília: Mec, s.d. 